\title{
Morphometrical Changes on Korean Rose Bitterling, Rhodeus uyekii, in Early Growth Period
}

\author{
${ }^{\dagger}$ In Bon Goo ${ }^{1}$, Sang Gu Lim ${ }^{1}$, Hyung Kyun Han ${ }^{1}$, and In-Seok Park ${ }^{2}$ \\ ${ }^{I}$ Inland Aquaculture Research Center, National Fisheries Research \& Development Institute (NFRDI), \\ Jinhae 645-758, Republic of Korea \\ ${ }^{2}$ Division of Marine Environment and Bioscience, Korea Maritime and Ocean University,
} Busan 606-791, Republic of Korea

\begin{abstract}
We investigated the process of yolk absorption in Korean rose bitterling, Rhodeus uyekii, and determined the changes in its morphometric characteristics. The $R$. uyekii from 1 days post hatching (DPH) to $21 \mathrm{DPH}$, the eye diameter (ED) was 5.4 at $5 \mathrm{DPH}$. Thereafter, the ED/total length (TL) ratio increased to 10.7 at $21 \mathrm{DPH}(p<0.05)$. The yolk length (YL) decreased from 95.4 to 1.1 by $21 \mathrm{DPH}$, and this rate of decrease was greater than that for any other dimension $(p<0.05) .12$ morphometric dimensions/TL for the $R$. uyekii were measured at each sampling day from $21 \mathrm{DPH}$ to $170 \mathrm{DPH}$. At just hatching, the average TL and BW were $6.1 \pm 0.09 \mathrm{~mm}$ and $4.9 \pm 0.07 \mathrm{mg}$, respectively. At $53 \mathrm{DPH}$, the average TL was $12.9 \pm 0.28 \mathrm{~mm}$ and the average $\mathrm{BW}$ was $14.7 \pm 0.72 \mathrm{mg}$; the total length growth equation was $\mathrm{TL}=5.507 \mathrm{e}^{0.038 \mathrm{t}}\left(R^{2}=0.916\right)$. Further, the body weight growth equation was $\mathrm{BW}=3.3647 \mathrm{e}^{0.0296 t}\left(R^{2}=0.9354\right)$. The dimensions with regard to body depth showed the greatest growth rates in the external characteristics of the fish $(p<0.05)$. The patterns of the morphometric characteristics measured in this study can be classified in three ways. The patterns were shown to be increased $(y=0.0992 \mathrm{x}+$ $12.07, R^{2}=0.8333$ ), decreased $\left(\mathrm{y}=-0.0569 \mathrm{x}+42.029, R^{2}=0.8395\right)$ or maintained $\left(\mathrm{y}=0.005 \mathrm{x}+18.263, R^{2}=0.3678\right)$ from $21 \mathrm{DPH}$ to 170 . These results will provide useful indices for the successful rearing of the $R$. uyekii.
\end{abstract}

Key words : Classical dimension, Early growth, Morphometrical change, Rhodeus uyekii, Truss dimension

\section{INTRODUCTION}

Morphological differences in groups and species are classified in terms of the overall body shape or specific morphoanatomical characteristics (Sträuss \& Bond, 1990). Among the body shape characteristics of fish, morphometric traits, unlike meristic traits, can be measured as mensural characteristics. Although the body shape of fish is largely determined by genetic factors (Riddell et al., 1981; Taylor
\& McPhail, 1985), the use of morphometric analyses to distinguish the genetically discrete groups within a fish species is limited by the difficulty of measuring the environmentally induced variations in the body shape (Ihssen et al., 1981; Currens et al., 1989; Park et al., 2001).

Both truss and classical dimensions are used to describe the body shapes of fish (Hubbs \& Lagler, 1947; Sträuss \& Bookstein, 1982). Truss dimensions consist of a systematically arranged set of distances that are measured between a set

\footnotetext{
Manuscript received 3 January 2014, Received in revised form 24 January 2014, Accepted 3 February 2014

${ }^{\dagger}$ Corresponding Author : In Bon Goo, Inland Aquaculture Research Center, National Fisheries Research \& Development Institute (NFRDI), Jinhae 645758, Republic of Korea. Tel. : +82-51-410-4321, Fax : +82-51-405-4322, E-mail : Bourne@kmou.ac.kr

This is an Open Access article distributed under the terms of the Creative Commons Attribution Non-Commercial License (http:// creativecommons.org/licenses/by-nc/3.0) which permits unrestricted non-commercial use, distribution, and reproduction in any medium, provided the original work is properly cited.
} 
of preselected anatomical landmarks (Sträuss \& Bookstein, 1982; Sträuss \& Bond, 1990). These landmarks are identified based on local morphological features and are chosen to divide the body into functional units (Sträuss \& Bond, 1990). Truss dimensions, which include components of body depth and length along the longitudinal axis, have theoretical advantages over classical morphometric characteristics in discriminating the different groups (Park et al., 2007).

Korean rose bitterling, Rhodeus uyekii, belongs to the family Cyprinidae. It is an endemic species that is found in the water system of nakdong river, Korea; furthermore, it likes flow slow, lush aquatic plants and mud at the edge of a river or reservoir pond (Jeon, 1982). The spawning season of R. uyekii is from April to June. During this period, females extend their ovipositor and spawning to the gill chamber of Unionidae fresh water bivalves, and male dense coloration (Uchida, 1939; Nakamura, 1969). The body shape of the $R$. uyekii is compressiform that has high body depth; usually, males have higher body depth than females. Further, males have a light brown body color at the dorsal region, and the caudal peduncle side has a dense color of silverlight. Males have black color in anal fin out side, and inside small light white, meanwhile female has not pattern. Therefore, males are particularly treated as aquarium fish because they have a visual effect. Recently, $R$. uyekii demand urgent conservation because easily exposure to biological and chemical pollution (Kang et al., 2006).

Early life history of the $R$. uyekii is as follows: reared in the laboratory, egg and larval development and seasonal sex ratio of Korean endemic fresh water fish $R$. uyekii, reproductive cycle of the spring-spawning bitterling, osteological study of $R$. uyekii, elongation of the ovipositor in $R$. uyekii, temperature-dependent index of mitotic interval $\left(\tau_{0}\right)$ for chromosome manipulation in R. uyekii and morphometric traits and cytogenetic analysis in induced cross and reciprocal hybrid between $R$. uyekii and $R$. notatus; all of these factors were studied with regard to the R. uyekii (Kim and Han, 1990; Park and Kim, 1990; An, 1995; Kim, 1997; Chae, 2001; Kim et al., 2011, 2012).

More information about the developmental stages of the $R$. uyekii is required because high levels of hatchery mortality are common during the early life stages. However, there have been no detailed reports. Because research into the early larval development of the $R$. uyekii is currently insufficient, in this study, we investigated the process of yolk absorption in $R$. uyekii, and also determined the changes in its morphometric characteristics.

\section{MATERIALS AND METHODS}

\section{Experimental fish}

R. uyekii broodstock was transported to a mariculture facility at the Fishery Genetics and Breeding Sciences Laboratory of the Korea Maritime and Ocean University in Busan, Republic of Korea, from Inland Aquaculture Research Center, National Fisheries Research \& Development Institute (NFRDI), Jinhae, Republic of Korea. The fish were raised in a glass tank (W $120 \mathrm{~cm} \times \mathrm{L} 30 \mathrm{~cm} \times \mathrm{H} 50 \mathrm{~cm}$ ) until the start of the experiment. The water temperature was maintained at $20 \pm 1{ }^{\circ} \mathrm{C}$.

\section{Artificial spawning and hatching}

Since the spawning season of the $R$. uyekii from late April to the middle of June 2013, dense colored males and ovipositor extended females were selected and used as broodstock. After the egg was from extended ovipositor female using the abdominal compression method, were inseminated using a wet method semen that through pressure on the abdomen of male were sorted within 2 minutes. A total of 2,000 eggs were reared in the plastic tank (Fresh Plus, Mirae Chemical, Republic of Korea)(W $30 \mathrm{~cm} \times \mathrm{L} 20 \mathrm{~cm} \times \mathrm{H} 15 \mathrm{~cm}$ ) until hatching. The water depth and L:D ratio were maintained at $10 \mathrm{~cm}$ and $13: 11$, res- 
pectively. The water in the hatch tank was replaced two times per day using aerated bottled water; further, the water temperature was maintained at $22 \pm 0.5^{\circ} \mathrm{C}$.

\section{Rearing conditions}

The hatched larvae each divided into 10 fish in the transparent plastic containers (Coolrara, Easyfilm, Republic of Korea)(W $10 \mathrm{~cm} \times \mathrm{L} 5 \mathrm{~cm} \times \mathrm{H} 3 \mathrm{~cm}$ ), and aeration bottled water (Natural mineral water, Pulmuone, Republic of Korea) was used for rearing, being replaced two times per day. Other rearing conditions were maintain under the same conditions of "Artificial spawning and hatching in this section," as previous stated. Since larvae feed at completely yolk absorption and the first feeding, 21 days post hatching (DPH), Artemia sp. was feeding. The water temperature was maintained at $22 \pm 0.5^{\circ} \mathrm{C}$; further, an analysis was made each day with regard to the average water temperature and integral water temperature during the rearing period.

\section{Specimens and morphometrical observation}

Newly hatched larvae $(n=50)$ were daily sampled from hatching to the DPH at 2 days interval from 7 to $21 \mathrm{DPH}$, at 4 days interval from 25 to $41 \mathrm{DPH}$, at 6 days interval from 47 to $83 \mathrm{DPH}$, and at 30 days interval from 110 to 170. Body outline measurements were made for 13 distances between landmarks for both truss and classical dimensions (Table 1, Fig. 1). Total length and body weight for the sampled larvae at different stages were measured to the nearest $0.01 \mathrm{~g}$ and $0.01 \mathrm{~cm}$ using an electric balance (AX 200, Shimadzu Corp., Japan) and a digital Vernier calipers

Table 1. Morphometric dimensions for Korean rose bitterling, Rhodeus uyekii, used in this experiment ${ }^{*}$

Morphometric dimensions

- Horizontal distance -

Total length

Horizontal distance between the most anterior extension of the head and the anterior insertion of the ventral fin

Horizontal distance between the most anterior extension of the head and the anterior insertion of the pectoral fin

Horizontal distance between the most anterior extension of the anal fin and the anterior insertion of the caudal fin Eye diameter

TL

HHAV

HHAP

HHAC

ED

\section{- Direct distance -}

\section{Truss dimension}

Most anterior extension of the head $\times$ longest point of gill cover from maxilla

Anterior insertion of primary dorsal fin $\times$ anterior insertion of the pectoral fin

Anterior insertion of primary dorsal fin $\times$ verticality position of the primary dorsal fin ray's anterior insertion

Anterior insertion of primary dorsal fin $\times$ anterior insertion of the ventral fin

Anterior insertion of primary dorsal fin $\times$ posterior insertion of the anal fin

\section{Classical dimension}

Most anterior extension of the head $\times$ anterior insertion of the primary dorsal fin

Most anterior extension of the head $\times$ verticality position of the primary dorsal fin ray's anterior insertion

\footnotetext{
* Each dimension is demonstrated in Fig. 1.
} 
(CD-20 CP; Mitutoyo, Japan), respectively. Prior to the measurements, the larvae were anaesthetized with $300 \mathrm{ppm}$ lidocaine- $\mathrm{HCl} / \mathrm{NaHCO}_{3}$ at $25^{\circ} \mathrm{C}$, according to the method of Park et al. (1988). Furthermore, a mimetic diagram was produced according to the growth for indicating the morphological changes.

The following horizontal distances were measured: total length (TL), the horizontal distance between the anteriormost head and the anterior insertion of the ventral fin (HHAV), the horizontal distance between the anteriormost extension of the head and the anterior insertion of the pectoral fin (HHAP), the horizontal distance between the anteriormost extension of the anal fin and the anterior insertion of the caudal fin (HHAC), and ED. Other distances (truss morphometric dimensions and classical morphometric dimensions) were direct distance measurements.

The external truss morphometric dimensions measured were as follows: $1 \times 8$, the anteriormost extension of the head $\times$ the longest point of the gill cover from the maxilla; $2 \times 7$, the anterior insertion of the primary dorsal fin $\times$ the anterior insertion of the pectoral fin; $2 \times 5$, the anterior insertion of the primary dorsal fin $\times$ the vertical position of the anterior insertion of the primary dorsal fin ray; $2 \times 6$, the anterior insertion of the primary dorsal fin $\times$ the anterior insertion of the ventral fin; $2 \times 4$, and the anterior insertion of the primary dorsal fin $\times$ the posterior insertion of the anal fin (Fig. 1A). Each external morphometric dimension was analyzed relative to the TL.

The external classical morphometric dimensions measured were as follows: $1 \times 2$, the anteriormost extension of the head $\times$ the anterior insertion of the primary dorsal fin; $1 \times$ 5 , the anteriormost extension of the head $\times$ the vertical position of the anterior insertion of the primary dorsal fin ray; and $2 \times 3$, the anterior insertion of the primary dorsal fin $\times$ the anterior insertion of the caudal fin (Fig. 1B). Each external morphometric dimensions was analyzed relative to the TL. The TL and the body weight of each larva were
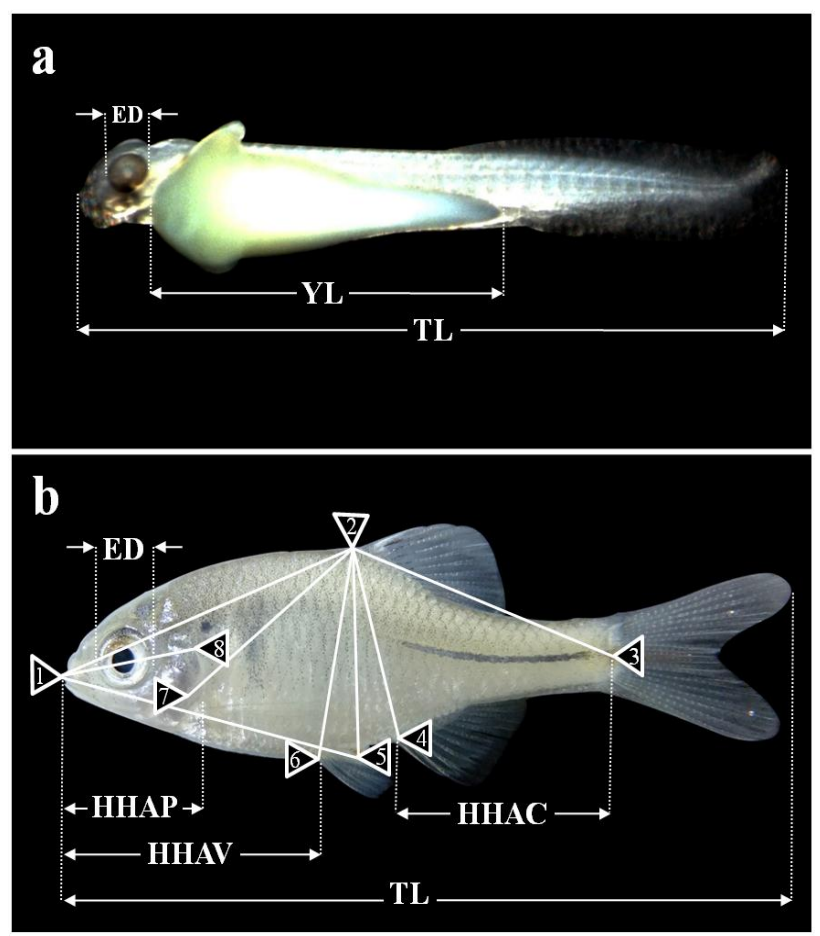

Fig. 1. Morphometric measurements between each landmark for the Korean rose bitterling, Rhodeus uyekii, in this study. Larva in the yolk stage (A) and juvenile stage (B). For abbreviations and each dimension between landmarks (indicated numbers), see Table 1. YL: yolk length.

measured, and their relationship, which indicated an exponential growth curve, was analyzed. The values given are morphometric dimensions/TL. In addition, the curves were drawn depending on the growth with the days post hatching; in particular, the main trendy dimensions were indicated as a linear function.

\section{Statistical analysis}

The study was performed in triplicate and the results are reported as means $\pm \mathrm{SD}(n=50)$, unless otherwise stated. The data were analyzed with a one-way analysis of variance (ANOVA) using the SPSS statistical package (SPSS 9.0, SPSS Inc., Chicago, IL, USA). The means were compared with Duncan's multiple range test and were considered significantly different at $p<0.05$. 


\section{RESULTS}

R. uyeii, hatched at two days $(48 \mathrm{~h})$ post fertilization with integral water temperature (IWT) after fertilization $43^{\circ} \mathrm{C}$. From just hatching (IWT after hatching $0{ }^{\circ} \mathrm{C}$ ) to 170 days post hatching (DPH)(IWT after hatching $\left.3,740{ }^{\circ} \mathrm{C}\right)$, the total length (TL) and body weight (BW) growth, showed in Fig. 2. At just hatching, the average TL and BW were each $6.1 \pm 0.09$ (SD) $\mathrm{mm}$ and $4.9 \pm 0.07$ (SD) $\mathrm{mg}$, respectively; at $170 \mathrm{DPH}$, the average TL was $12.9 \pm 0.28$ (SD) $\mathrm{mm}$ and the average $\mathrm{BW}$ was $14.7 \pm 0.72$ (SD) $\mathrm{mg}$. Total length showed continuous growth from just hatching to $53 \mathrm{DPH}$; the total length growth equation was $\mathrm{TL}=$ $5.507 \mathrm{e}^{0.038 \mathrm{t}}\left(R^{2}=0.916\right)(\mathrm{TL}$, total length; $\mathrm{t}$, time)(Fig. $1 \mathrm{~A})$. Body weight was slightly reduced from just hatching to completely yolk absorption time, but after feeding began, it rapidly increased. The body weight growth equation was $\mathrm{BW}=3.3647 \mathrm{e}^{0.0296 \mathrm{t}}\left(R^{2}=0.9354\right)(\mathrm{BW}$, body weight; $\mathrm{t}$, time $)$ (Fig. 1A). Yolk absorption is complete at $21 \mathrm{DPH}\left(462^{\circ} \mathrm{C}\right.$ IWT), and showed a larvae form. The increases in TL and BW showed a positive relationship. TL increased by 10.6 $\mathrm{mm}$ from $21 \mathrm{DPH}$ to $170 \mathrm{DPH}$. Thereafter, the Korean rose bitterling ultimately grew to $23.9 \mathrm{~mm}$ (Fig. 2). The BW of the Korean rose bitterling had increased to 253.2

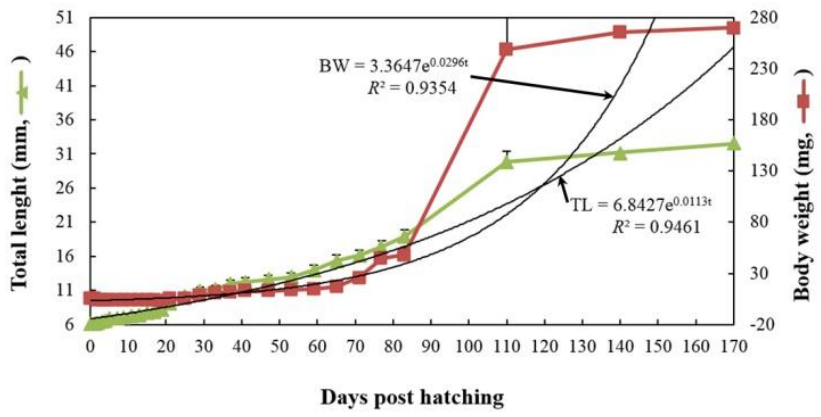

Fig. 2. Growth curves in total length and body weight of the Korean rose bitterling, Rhodeus uyekii, from hatching to 170 days post hatching. Means \pm $\mathrm{SD}(n=50)$ of triplicate groups. Vertical bars represent standard deviations. TL, total length; BW, body weight; $\mathrm{t}$, time. mg at a steady rate by $170 \mathrm{DPH}$ (Fig. 2). Further, the rate of the increase in TL was more regular than the increase in BW (Fig. 2).

Table 2 lists two morphometric dimensions/TL for the Korean rose bitterling from $1 \mathrm{DPH}$ to $21 \mathrm{DPH}$. In this experiment, the eye diameter (ED) was 5.4 at $5 \mathrm{DPH}$. Thereafter, the ED/TL ratio increased to 10.7 at $21 \mathrm{DPH}(p<$ 0.05). Yolk length (YL) decreased from 95.4 to 1.1 by 21 $\mathrm{DPH}$, and this rate of decrease was greater than that for any other dimension $(p<0.05)$. Table 3 lists 12 morphometric dimensions/TL for the Korean rose bitterling, which were measured at each sampling day from $21 \mathrm{DPH}$ to $170 \mathrm{DPH}$.

Table 2. Results of 2 characteristics in Korean rose bitterling, Rhodeus uyekii, from 1 day to 21 days post hatching*

\begin{tabular}{ccc}
\hline \hline \multirow{2}{*}{$\begin{array}{c}\text { Day post } \\
\text { hatching }\end{array}$} & Morphometric dimension/TL (\%) \\
\hline 1 & ED & YL \\
\hline 2 & - & $95.4 \pm 3.12^{\mathrm{A}}$ \\
3 & - & $94.7 \pm 2.50^{\mathrm{A}}$ \\
4 & - & $91.9 \pm 2.92^{\mathrm{B}}$ \\
5 & $5.4 \pm 0.70^{\mathrm{A}}$ & $89.1 \pm 1.10^{\mathrm{B}}$ \\
7 & $6.6 \pm 0.74^{\mathrm{B}}$ & $87.8 \pm 3.14^{\mathrm{B}}$ \\
9 & $7.0 \pm 0.80^{\mathrm{C}}$ & $85.5 \pm 2.66^{\mathrm{C}}$ \\
11 & $7.4 \pm 0.85^{\mathrm{C}}$ & $76.7 \pm 2.25^{\mathrm{D}}$ \\
13 & $7.6 \pm 0.86^{\mathrm{C}}$ & $66.4 \pm 2.73^{\mathrm{E}}$ \\
15 & $7.4 \pm 0.73^{\mathrm{C}}$ & $50.4 \pm 1.14^{\mathrm{F}}$ \\
17 & $7.7 \pm 0.76^{\mathrm{C}}$ & $38.5 \pm 1.12^{\mathrm{G}}$ \\
19 & $7.5 \pm 0.98^{\mathrm{C}}$ & $19.5 \pm 1.98^{\mathrm{H}}$ \\
21 & $7.9 \pm 0.61^{\mathrm{C}}$ & $1.1 \pm 1.13^{\mathrm{I}}$ \\
\hline
\end{tabular}

* The values are means \pm SD $(n=50)$ of triplicate groups. Different capital letters on the values indicate statistical significance among days post hatching $(p<0.05)$. Each dimension is demonstrated in Fig. 1. ED: eye diameter, TL: total length, YL: yolk length. 
IB Goo, SG Lim, HK Han, I-S Park

Table 3. Results of 11 characteristics in Korean rose bitterling, Rhodeus uyekii, by days post hatching*

\begin{tabular}{|c|c|c|c|c|c|c|c|c|c|c|c|c|}
\hline \multirow{2}{*}{$\begin{array}{l}\text { Day post } \\
\text { hatching }\end{array}$} & \multicolumn{12}{|c|}{ Morphometric dimension/TL (\%) } \\
\hline & HHAP & HHAV & HHAC & $1 \times 2$ & $1 \times 8$ & $1 \times 5$ & $2 \times 7$ & $2 \times 5$ & $2 \times 6$ & $2 \times 4$ & $2 \times 3$ & $\mathrm{ED}$ \\
\hline 21 & $14.7 \pm 2.26^{\mathrm{Ab}}$ & $42.9 \pm 2.06^{\mathrm{Aa}}$ & $36.9 \pm 1.04^{\mathrm{Ac}}$ & $41.4 \pm 1.28^{\mathrm{Ad}}$ & $18.6 \pm 1.36^{\mathrm{Ac}}$ & $41.4 \pm 2.16^{\mathrm{Af}}$ & $27.1 \pm 1.06^{\mathrm{Ag}}$ & $11.4 \pm 1.85^{\mathrm{Ah}}$ & $12.1 \pm 2.61^{\mathrm{Ab}}$ & $11.8 \pm 1.26^{\mathrm{Ai}}$ & $46.4 \pm 1.28^{\mathrm{Aj}}$ & $7.9 \pm 0.61^{\mathrm{Ak}}$ \\
\hline 25 & $15.9 \pm 3.82^{\mathrm{Bb}}$ & $41.0 \pm 2.32^{\mathrm{Ba}}$ & $36.0 \pm 0.78^{\mathrm{Bc}}$ & $41.0 \pm 1.68^{\mathrm{Bd}}$ & $18.0 \pm 1.72^{\mathrm{Be}}$ & $41.0 \pm 2.76^{\mathrm{Bf}}$ & $27.0 \pm 1.32^{\mathrm{Bg}}$ & $12.1 \pm 1.57^{\mathrm{Ah}}$ & $12.4 \pm 1.96^{\mathrm{Bb}}$ & $13.0 \pm 1.06^{\mathrm{Ai}}$ & $44.0 \pm 1.76^{\mathrm{Aj}}$ & $7.4 \pm 0.96^{\mathrm{Bk}}$ \\
\hline 29 & $16.7 \pm 3.17^{\mathrm{Bb}}$ & $41.1 \pm 2.35^{\mathrm{Ba}}$ & $35.3 \pm 1.45^{\mathrm{Bc}}$ & $41.8 \pm 1.45^{\mathrm{Bd}}$ & $18.1 \pm 1.23^{\mathrm{Be}}$ & $41.1 \pm 1.45^{\mathrm{Bf}}$ & $27.1 \pm 1.35^{\mathrm{Bg}}$ & $13.6 \pm 1.35^{\mathrm{Ah}}$ & $15.6 \pm 1.89^{\mathrm{Bb}}$ & $13.1 \pm 1.98^{\mathrm{Bi}}$ & $43.1 \pm 1.45^{\mathrm{Bj}}$ & $7.6 \pm 0.89^{\mathrm{Ck}}$ \\
\hline 33 & $17.7 \pm 2.56^{\mathrm{Bb}}$ & $40.3 \pm 2.90^{\mathrm{Ba}}$ & $35.5 \pm 1.10^{\mathrm{Bc}}$ & $42.5 \pm 0.77^{\mathrm{Bd}}$ & $18.3 \pm 1.51^{\mathrm{Be}}$ & $40.4 \pm 2.66^{\mathrm{Bf}}$ & $27.3 \pm 1.90^{\mathrm{Bg}}$ & $14.8 \pm 1.54^{\mathrm{Ah}}$ & $15.5 \pm 2.87^{\mathrm{Bb}}$ & $17.3 \pm 1.03^{\mathrm{Bi}}$ & $43.6 \pm 1.66^{\mathrm{Bj}}$ & $7.5 \pm 0.87^{\mathrm{Ck}}$ \\
\hline 37 & $17.3 \pm 2.01^{\mathrm{Bb}}$ & $40.9 \pm 3.06^{\mathrm{Ba}}$ & $34.7 \pm 1.43^{\mathrm{Bc}}$ & $41.4 \pm 1.12^{\mathrm{Bd}}$ & $18.9 \pm 2.66^{\mathrm{Be}}$ & $40.5 \pm 1.06^{\mathrm{Bf}}$ & $26.9 \pm 2.06^{\mathrm{Bg}}$ & $15.5 \pm 1.43^{\mathrm{Ah}}$ & $17.6 \pm 1.01^{\mathrm{Bb}}$ & $17.9 \pm 1.47^{\mathrm{Bi}}$ & $42.5 \pm 2.06^{\mathrm{Bj}}$ & $7.6 \pm 0.01^{\mathrm{Ck}}$ \\
\hline 43 & $17.7 \pm 3.18^{\mathrm{Bb}}$ & $39.3 \pm 2.43^{\mathrm{Ba}}$ & $33.1 \pm 1.59^{\mathrm{Bc}}$ & $41.5 \pm 0.84^{\mathrm{Bd}}$ & $18.3 \pm 2.44^{\mathrm{Be}}$ & $40.1 \pm 1.42^{\mathrm{Bf}}$ & $27.3 \pm 1.43^{\mathrm{Bg}}$ & $16.5 \pm 1.12^{\mathrm{Ah}}$ & $17.4 \pm 2.94^{\mathrm{Bb}}$ & $18.3 \pm 1.51^{\mathrm{Bi}}$ & $42.1 \pm 3.42^{\mathrm{Cj}}$ & $7.4 \pm 0.94^{\mathrm{Dk}}$ \\
\hline 49 & $17.7 \pm 2.44^{\mathrm{Bb}}$ & $39.5 \pm 3.11^{\mathrm{Ba}}$ & $33.6 \pm 1.47^{\mathrm{Bc}}$ & $42.9 \pm 1.22^{\mathrm{Bd}}$ & $18.5 \pm 2.21^{\mathrm{Be}}$ & $40.8 \pm 2.91^{\mathrm{Bf}}$ & $27.5 \pm 1.11^{\mathrm{Bg}}$ & $17.7 \pm 1.12^{\mathrm{Ah}}$ & $18.7 \pm 2.61^{\mathrm{Bb}}$ & $19.5 \pm 1.45^{\mathrm{Bi}}$ & $42.8 \pm 4.91^{\mathrm{Cj}}$ & $7.7 \pm 0.61^{\mathrm{Dk}}$ \\
\hline 53 & $17.1 \pm 2.69^{\mathrm{Bb}}$ & $38.8 \pm 2.52^{\mathrm{Ba}}$ & $32.9 \pm 0.86^{\mathrm{Bc}}$ & $41.4 \pm 1.23^{\mathrm{Bd}}$ & $18.8 \pm 2.52^{\mathrm{Be}}$ & $40.4 \pm 2.02^{\mathrm{Bf}}$ & $27.8 \pm 1.52^{\mathrm{Bg}}$ & $18.4 \pm 1.86^{\mathrm{Ah}}$ & $18.1 \pm 2.12^{\mathrm{Bb}}$ & $20.8 \pm 1.85^{\mathrm{Bi}}$ & $42.4 \pm 3.02^{\mathrm{Cj}}$ & $7.1 \pm 0.12^{\mathrm{Dk}}$ \\
\hline 59 & $17.2 \pm 2.11^{\mathrm{Bb}}$ & $37.4 \pm 2.16^{\mathrm{Ba}}$ & $32.3 \pm 0.61^{\mathrm{Bc}}$ & $42.7 \pm 0.36^{\mathrm{Bd}}$ & $18.4 \pm 2.16^{\mathrm{Be}}$ & $40.6 \pm 2.67^{\mathrm{Bf}}$ & $28.4 \pm 1.16^{\mathrm{Bg}}$ & $18.3 \pm 1.44^{\mathrm{Ah}}$ & $19.3 \pm 2.51^{\mathrm{Bb}}$ & $21.4 \pm 1.52^{\mathrm{Bi}}$ & $42.6 \pm 6.67^{\mathrm{Cj}}$ & $7.3 \pm 0.51^{\mathrm{Dk}}$ \\
\hline 65 & $17.5 \pm 2.38^{\mathrm{Bb}}$ & $37.6 \pm 1.67^{\mathrm{Ba}}$ & $31.2 \pm 0.76^{\mathrm{Bc}}$ & $42.3 \pm 1.89^{\mathrm{Bd}}$ & $18.6 \pm 2.67^{\mathrm{Be}}$ & $40.7 \pm 2.87^{\mathrm{Bf}}$ & $28.6 \pm 1.67^{\mathrm{Bg}}$ & $19.7 \pm 1.48^{\mathrm{Ah}}$ & $21.5 \pm 2.12^{\mathrm{Bb}}$ & $22.6 \pm 1.71^{\mathrm{Bi}}$ & $41.7 \pm 6.87^{\mathrm{Cj}}$ & $7.5 \pm 0.12^{\mathrm{Dk}}$ \\
\hline 71 & $17.1 \pm 1.83^{\mathrm{Bb}}$ & $36.7 \pm 2.61^{\mathrm{Ba}}$ & $32.5 \pm 1.47^{\mathrm{Bc}}$ & $42.1 \pm 1.62^{\mathrm{Bd}}$ & $18.7 \pm 2.61^{\mathrm{Be}}$ & $41.6 \pm 2.17^{\text {Bf }}$ & $29.7 \pm 1.61^{\mathrm{Bg}}$ & $20.9 \pm 1.95^{\mathrm{Ch}}$ & $23.9 \pm 2.56^{\mathrm{cb}}$ & $23.7 \pm 1.77^{\mathrm{Bi}}$ & $41.6 \pm 4.17^{\mathrm{Cj}}$ & $7.9 \pm 0.56^{\mathrm{Dk}}$ \\
\hline 77 & $17.8 \pm 2.12^{\mathrm{Bb}}$ & $36.3 \pm 2.43^{\mathrm{Ba}}$ & $31.1 \pm 1.44^{\mathrm{Bc}}$ & $42.0 \pm 0.78^{\mathrm{Bd}}$ & $18.3 \pm 2.43^{\mathrm{Be}}$ & $41.5 \pm 2.82^{\mathrm{Bf}}$ & $28.3 \pm 1.43^{\mathrm{Bg}}$ & $21.2 \pm 1.68^{\mathrm{Ch}}$ & $25.1 \pm 2.22^{\mathrm{Cb}}$ & $24.3 \pm 1.19^{\mathrm{Ci}}$ & $41.5 \pm 4.82^{\mathrm{Cj}}$ & $7.1 \pm 0.22^{\mathrm{Dk}}$ \\
\hline 83 & $17.5 \pm 2.18^{\mathrm{Bb}}$ & $36.0 \pm 1.88^{\mathrm{Ba}}$ & $32.5 \pm 0.84^{\mathrm{Bc}}$ & $41.7 \pm 0.99^{\mathrm{Bd}}$ & $19.0 \pm 1.88^{\mathrm{Be}}$ & $41.7 \pm 1.91^{\mathrm{Bf}}$ & $29.0 \pm 1.88^{\mathrm{Bg}}$ & $22.6 \pm 1.79^{\mathrm{Ch}}$ & $24.9 \pm 2.26^{\mathrm{Cb}}$ & $25.0 \pm 1.29^{\mathrm{Ci}}$ & $41.7 \pm 6.91^{\mathrm{Cj}}$ & $7.9 \pm 0.26^{\mathrm{Dk}}$ \\
\hline 110 & $17.4 \pm 1.59^{\mathrm{Bb}}$ & $35.4 \pm 2.09^{\mathrm{Ca}}$ & $32.1 \pm 0.96^{\mathrm{Bc}}$ & $42.6 \pm 0.80^{\mathrm{Bd}}$ & $19.2 \pm 1.38^{\mathrm{Be}}$ & $44.2 \pm 1.06^{\mathrm{Bf}}$ & $30.2 \pm 2.25^{\mathrm{Cg}}$ & $25.9 \pm 1.67^{\mathrm{Dh}}$ & $26.5 \pm 1.66^{\mathrm{Cb}}$ & $25.0 \pm 1.82^{\mathrm{Ci}}$ & $40.0 \pm 0.89^{\mathrm{Cj}}$ & $7.2 \pm 0.25^{\mathrm{Dk}}$ \\
\hline 140 & $16.3 \pm 0.86^{\mathrm{Bb}}$ & $34.8 \pm 0.76^{\mathrm{Ca}}$ & $32.3 \pm 1.43^{\mathrm{Bc}}$ & $42.4 \pm 0.66^{\mathrm{Bd}}$ & $19.0 \pm 0.80^{\mathrm{Be}}$ & $40.9 \pm 2.32^{\mathrm{Bf}}$ & $30.3 \pm 1.46^{\mathrm{Cg}}$ & $24.9 \pm 1.65^{\mathrm{Dh}}$ & $25.9 \pm 1.62^{\mathrm{Cb}}$ & $23.3 \pm 1.71^{\mathrm{Ci}}$ & $40.6 \pm 0.57^{\mathrm{Cj}}$ & $7.9 \pm 0.36^{\mathrm{Dk}}$ \\
\hline 170 & $15.3 \pm 1.24^{\mathrm{Ab}}$ & $33.9 \pm 2.28^{\mathrm{Ca}}$ & $32.1 \pm 1.23^{\mathrm{Bc}}$ & $42.3 \pm 2.22^{\mathrm{Bd}}$ & $18.8 \pm 2.12^{\mathrm{Be}}$ & $40.9 \pm 2.01^{\mathrm{Bf}}$ & $31.0 \pm 0.86^{\mathrm{Cg}}$ & $25.3 \pm 1.07^{\mathrm{Dh}}$ & $26.5 \pm 1.42^{\mathrm{Cb}}$ & $24.7 \pm 1.05^{\mathrm{Ci}}$ & $39.9 \pm 1.64^{\mathrm{Cj}}$ & $6.6 \pm 0.67^{\mathrm{Dk}}$ \\
\hline
\end{tabular}

*For abbreviations and each dimension, see Table 1 and Fig. 1 . The values are means \pm SD $(n=50)$ of triplicate groups. Data were analyzed using one- and two-way ANOVA on data transformed to the arcsine of the square root. Different capital letters on the values indicate statistical significance among days post hatching $(p<0.05)$. Different small letters on the values indicate statistical significance among ratios of morphometric dimension/total length (TL) $(p<0.05)$.

The horizontal distance between the most anterior extension of the head and the anterior insertion of the pectoral fin (HHAP), most anterior extension of the head $\times$ anterior insertion of the primary dorsal fin $(1 \times 2)$, most anterior extension of the head $\times$ longest point of gill cover from maxilla $(1 \times 8)$, most anterior extension of the head $\times$ verticality position of the primary dorsal fin ray's anterior insertion $(1 \times 5)$, and ED did not differ significantly from $31 \mathrm{DPH}$ to $170 \mathrm{DPH}(p>0.05)$. During $170 \mathrm{DPH}$, the horizontal distance between the most anterior extension of the head and the anterior insertion of the ventral fin (HHAV), horizontal distance between the most anterior extension of the anal fin and the anterior insertion of the caudal fin (HHAC) and anterior insertion of primary dorsal fin $\times$ anterior insertion of the caudal fin $(2 \times 3)$ decreased gradually, whereas the anterior insertion of primary dorsal fin $\times$ anterior insertion of the pectoral fin $(2 \times 7)$, anterior insertion of primary dorsal fin $\times$ verticality position of the primary dorsal fin ray's anterior insertion $(2 \times 5)$, anterior insertion of primary dorsal fin $\times$ anterior insertion of the ventral fin $(2 \times 6)$ and anterior insertion of primary dorsal fin $\times$ posterior insertion of the anal fin $(2 \times 4)$ gradually increased significantly $(p<0.05)$. The dimension $2 \times 7$ increased to $130.6 \%, 2 \times 5$ increased to $240.2 \%, 2 \times 6$ increased to $231.2 \%$ and $2 \times 4$ increased to $229.3 \%$; these dimensions conveyed the greatest growth rates in the external characteristics of fish, respectively $(p<0.05)$.

The relationship between YL/TL and DPH was $\mathrm{y}=-4.375 \mathrm{x}$ $+111.0, R^{2}=0.894$ (y is YL/TL, $\mathrm{x}$ is days post hatching) (Fig.

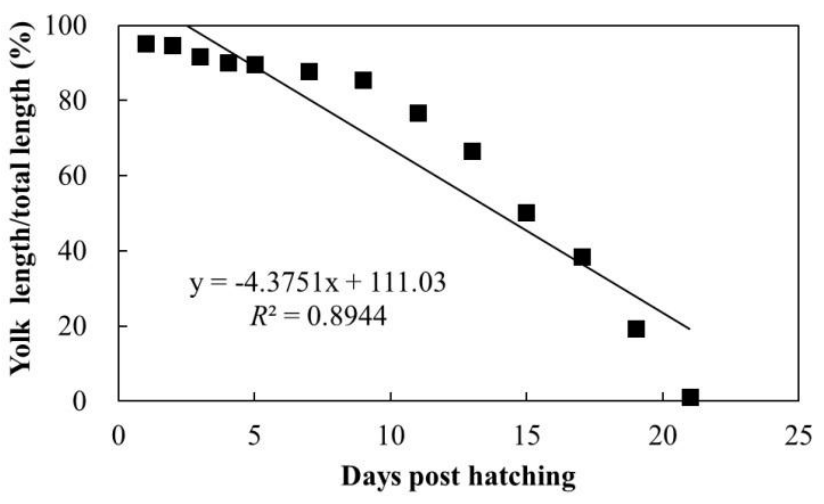

Fig. 3. Relationship between yolk length per total length and days post hatching in the Korean rose bitterling, Rhodeus uyekii, from hatching to 21 days post hatching. $\mathrm{Y}=-4.375 \mathrm{X}+111.0, R^{2}=0.894$ ( $\mathrm{Y}$ is yolk length per total length, $\mathrm{X}$ is days post hatching). 


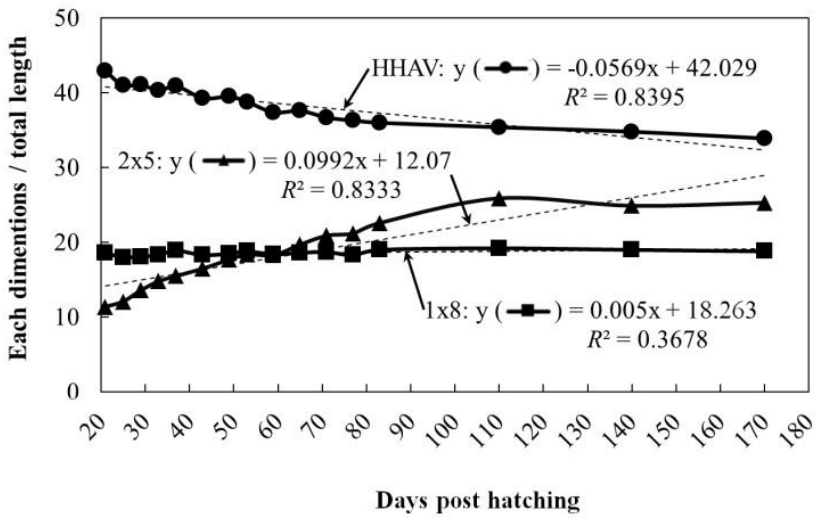

Fig. 4. Relationship between days post hatching and horizontal distance between the most anterior extension of the head and the anterior insertion of the ventral fin $(\mathrm{HHAV})\left(\mathrm{y}=\mathbf{0 . 0 9 9 2 x}+\mathbf{1 2 . 0 7}, R^{2}=\mathbf{0 . 8 3 3 3}\right)$, anterior insertion of primary dorsal fin $x$ verticality position of the primary dorsal fin ray's anterior insertion $(2 \times 5)\left(y=-0.0569 x+42.029, R^{2}=0.8395\right)$, and most anterior extension of the head $\times$ longest point of gill cover from maxilla $(1 \times 8)(y=0.005 x+18.263$, $R^{2}=0.3678$ ) in the Korean rose bitterling, Rhodeus uyekii, from 21 days post hatching (DPH) to 170 DPH ( $y$ is each dimension/ total length, $x$ is days post hatching).

3). As shown in Fig. 4, the patterns of the morpho-metric characteristics measured in this study can be classified in three ways. HHAV, $1 \times 8$ and $2 \times 5$ are the main traits of each curve, and patterns were shown increased $(\mathrm{y}=0.0992 \mathrm{x}+$ $\left.12.07, R^{2}=0.8333\right)$, decreased $\left(\mathrm{y}=-0.0569 \mathrm{x}+42.029, R^{2}=\right.$ $0.8395)$ or maintained $\left(\mathrm{y}=0.005 \mathrm{x}+18.263, R^{2}=0.3678\right)$ from $21 \mathrm{DPH}$ to $170 \mathrm{DPH}$ (Fig. 4)

\section{DISCUSSION}

The time taken for the hatching of the R. uyekii, was 48 h in $22 \pm 1{ }^{\circ} \mathrm{C}$, which was a similar result to Kim \& Han (1990), which reported $50 \mathrm{~h}$ in $17.5 \pm 1{ }^{\circ} \mathrm{C}$, and Suzuki et al., (1985) $46 \mathrm{~h}$ in $22 \pm 1{ }^{\circ} \mathrm{C}$. This result is relative more longer or shorter than that of previous research on other species of rose bitterling, $R$. ocellatus, $39 \mathrm{~h}$ in 17.8 18.0; slender bitterling, Acheilognathus lanceolatus, $84 \mathrm{~h}$ in $17 \sim 21{ }^{\circ} \mathrm{C}$; flat bitterling, Paracheilognathus rhombea, $96 \mathrm{~h}$ in 16 $19^{\circ} \mathrm{C}$. It seems that the time taken for hatching was affected by the water temperature and different inter species. Makeyeve (1976) reported that the yolk sac larvae yolk bump was to prevent the drop out from the shellfish gill chamber as an anchor. In this experiment, even though taken the larvae what through artificial spawning and rearing, appeared yolk bump. In particular, a yolk bump will be important to distinguish the trait of Rhodeus compared with other Genus.

The truss dimensions are the primary units of classifycation for the external anatomical markers that are normally assessed in fish (Sträuss \& Bond, 1990). The truss dimensions are the length measurements that refer to the ratios between the width of the fish's body and the axis of the fish's length. Theoretically, the truss dimensions are a better measurement of the shapes of fish than the classical dimensions (Sträuss \& Bookstein, 1982; Currens et al., 1989).

The combined morphometric traits of the $R$. uyekii showed a tendency to increase from 21 days post hatching (DPH) to $170 \mathrm{DPH}$ (Table 3). Although limited, research related to the early growth of the $R$. uyekii has shown that when they hatch, they absorb the whole yolk sac and then begin to emerge (Dill, 1969; Brannon, 1972; Zhang et al., 1995). However, it is unclear how the yolk sac changes in shape from the start of its absorption. In this study, yolk length (YL) decreased with time. After hatching, $\mathrm{YH}$ also decreased, but the reduction was smaller than that in YL. This decrease in yolk means that, as in the larvae, the juvenile reverts from endogenous feeding to exogenous feeding after the yolk sac declines (Dill, 1969; Brannon, 1972; Zhang et al., 1995). It is generally reported that the absorptive function of the alimentary canal in fish is initiated either before or after the absorption of the yolk sac. In juvenile Coregonus fera, the yolk sac is completely 
absorbed after $11 \mathrm{DPH}$, and during this period, the absorptive function of the midgut epithelium begins to function (Loewe \& Eckmann, 1988).

A morphometrical study of the early growth period was reported on cyprinid loach, Misgurnus anguillicaudatus, Ussurian bullhead, Leiocassis ussuriensis and Korean bullhead, Pseudobagrus fulvidraco (Han et al., 2013; Lim et al., 2013). As mentioned earlier with Han et al. (2013) and Lim et al. (2013), in cyprinid loach, dimensions with regard to body length were significantly increased during early growth 60 DPH $(p<0.05)$, and Ussurian bullhead and Korean bullhead were growth to constant ratio in early growth period after maintain, on the other hand $R$. uyekii shown dimensions about body depth gradually increasing, and relatively dimensions about body length decreasing trend in early growth period.

As aforementioned, there has been insufficient research into the early growth of $R$. uyekii In this study, morphometric characteristics as well as the absorption of the yolk sac were investigated from $1 \mathrm{DPH}$ to 170 . These results will provide useful indices for the successful rearing of the R. uyekii.

\section{ACKNOWLEDGMENTS}

This research was supported by a research grant (RP2014-AQ-022) from the Inland Aquaculture Research Center, National Fisheries Research \& Development Institute (NFRDI), Republic of Korea. The comments of the anonymous reviewers greatly improved the quality of the manuscript. We declare that all experiments in this study comply with the current laws of the Republic of Korea (Ordinance of Agriculture, Food and Fisheries, No. 1, Regarding Experimental Animals, No. 9,932).

\section{REFERENCES}

An CH (1995) Reproductive cycle of the spring-spawning bitterling, Rhodeus uyekii (Pisces: Cyprinidae). Kor J Ichthyol 7:33-42.

Brannon EL (1972) Mechanisms controlling migration of sockeye salmon fry. Int Pacific Salmon Fish Comm Bull 21:86.

Chae BS (2001) Elongation of the ovipositor in Korean rose bitterling, Rhodeus uyekii (Pisces: Cyprinidae). Kor J Ichthyol 13:111-116.

Currens KP, Sharpe CS, Hjort R, Schreek CB, Li HW (1989) Effect of different feeding regimes on the morphometrics of chinook salmon Oncorhynychus tshawytscha and rainbow trout, Oncorhynchus mykiss. Copeia 3: 689-695.

Dill LM (1969) The sub-gravel behaviour of Pacific salmon larvae. In: Northcote TG (ed.), Symposium on Salmon and Trout in Streams, H. R. MacMillan Lectures in Fisheries, 1968, University of British Columbia, Vancouver, pp. 89-99.

Han HK, Lim SG, Kang JH, Choi JW, Gil HW, Cho SH, Lim S-Y, Park I-S (2013) Morphometric and histological changes in cyprinid loach, Misgurnus anguillicaudatus, in the early growth period. Dev Reprod 17:187-198.

Hubbs CL, Lagler KF (1947) Fishes of the Great Lakes region. Cranbrook Instit Sci 26:186.

Ihssen PE, Booke HE, Casslman JM, McGlade JM, Payne NR, Utter FM (1981) Stock identification: materials and methods. Can J Fish Aquat Sci 38:1838-1855.

Jeon SR (1982) Studies on the distribution of the Acheilognathid fishes (Cyprinidae) from Korea. Ann Rep Biol Res 3:33-47.

Kang EJ, Kim CH, Park I-S, Yang H, Cho YC (2006) Early developmental characteristics of induced hybrids between Rhodeus uyekii and R. notatus (Pisces: Cyprinidae). Kor J Ichthyol 18:339-346.

Kim BS, Lim S-G, Gil HW, Park I-S (2011) Temperaturedependent index of mitotic interval $\left(\tau_{0}\right)$ for chromosome 
manipulation in Korean rose bitterling, Rhodeus uyekii. J Fish Aquat Sci 14:429-434.

Kim BS, Kang EJ, Jang H, Park I-S (2012) Morphometric traits and cytogenetic analysis in induced cross and reciprocal hybrid between Rhodeus uyekii and $R$. notatus. Kor J Ichthyol 24:151-159.

Kim IJ (1997) A osteological study of Rhodeus uyekii. Kor J Ichthyol 9:130-140.

Kim YU, Han KH (1990) Early life history of the Korean bitterling, Rhodeus uyekii (Cyprinidae), reared in the laboratory. Kor J Ichthyol 2:159-168.

Lim SG, Han HK, Kang JH, Park HJ, Oh JS, Lim JS, Goo IB , Park I-S (2013) Comparative analysis of the morphometric changes in Ussurian bullhead, Leiocassis ussuriensis, and Korean bullhead, Pseudobagrus fulvidraco, in the early period of growth. Dev Reprod 17:257-268.

Loewe H, Eckmann R (1988) The ontogeny of the alimentary tract of coregonid larvae: normal development. J Fish Biol 33:841-850.

Makeyeva AP (1976) Characteristics of the early development stages of a bitterling, Rhodeus ocellatus new to the ichthyofauna of the USSR. J Ichthyol 16:756-767.

Nakamura, M. (1969) Cyprinid fishes of Japan. Studies on the life history of Cyprinid fished of Japan. Res Ins Nat Res, Tokyo, pp. 5-99.

Park I-S, Im JM, Ryu DK, Nam YK, Kim DS (2001) Effect of starvation on morphmetric changes in Rhynchocypris oxycephalus (Sauvage and Dabry). J Appl Ichthyol 17:277-281.

Park I-S, Kim JM, Kim YH Kim DS (1988). Influence of lidocaine as an anaesthetic for marine fishes. J Fish Pathol 1:123-130.

Park I-S, Woo SR, Song YC, Cho SH (2007) Effects of starvation on the morphometric characteristics of olive flounder, Paralichthys olivaceus. Ichthyol Res 54:297302.

Park KN, Kim CH (1990) Egg and larval development and seasonal sex ratio of Korean endemic fresh water fish, Rhodeus uyekii. J Natural Sci Res Ins 3:29-33.

Riddell BE, Leggett WC, Saunders RL (1981) Evidence of adaptive polygenic variation between two populations of Atlantic salmon, Salmo salar native to tributaries of the SW Miramichi river, NB. Can J Fish Aquat Sci $38: 321-333$

Sträuss RE, Bond CE (1990) Taxonomic methods, morphology. Methods for fish biology, American Fish Society, Bethesda, MD, USA. pp 125-130.

Sträuss RE, Bookstein FL (1982) The truss: body from reconstructions in morphometrics. Syst Zool 31:113135.

Suzuki N, Akiyama N, Hibiya T (1985) Development of the bitterling, Rhodeus uyekii Cyprinidae with a note on minute tubercles on the skin surface. Japan J Ichthyol. $32: 28-34$

Taylor EB, McPhail JD (1985) Variation in burst and prolonged swimming performance among British Columbia populations of coho salmon, Oncorhynchus kisutch. Can J Fish Aquat Sci 42:2029-2033.

Uchida K (1939). The fished of Tyosen. Part 1. Nematognathi and eventognathi. Bull Fish Exp State 6, pp. 88177.

Zhang CI, Sohn MH, Seong KB, Park I-S (1995) Yolk absorption and growth of chum salmon, Oncorhynchus keta alevin. Kor J Fish Aquat Sci 28:539-548. (in Korean with an English abstract) 